\title{
Karakter Pendidikan untuk Membentuk Pendidikan Karakter
}

\author{
Abdul Jalil \\ Sekolah Tinggi Agama Islam Negeri Kudus
}

\begin{abstract}
Existence of madrasa over time increasingly eroded by the waves 'leveling' on behalf of accreditation. As an initiative to defend against scour vision of civilization, educational institution of Qudsiyyah finally returned to khittah to establish Ma'had Qudsiyyah in Kudus which concentrates on aspects of ulümul fiqh. Goals to be achieved is a man of character formation intact (al-Kaun al-jami') and the balance between mind and heart, body and spirit, skill and character, as well as cognitive, affective and psychomotor. Ma'had Qudsiyyah have set up processes and educational management that reflects management measures, implementation strategies, readiness of human resources of education and education, indicators of success of the program, design a comprehensive program contains content and contextual analysis of the educational process, technical evaluation and monitoring programs and policy formulation.
\end{abstract}

Keywords: $\quad$ boarding, character education, character education

\begin{abstract}
Abstrak
Eksistensi madrasah dari waktu ke waktu semakin tergerus oleh gelombang 'penyamarataan' atas nama akreditasi. Sebagai ikhtiar untuk mempertahankan visinya melawan gerusan peradaban, lembaga pendidikan Qudsiyyah akhirnya kembali ke khittah dengan mendirikan Ma'had Qudsiyyah Menara Kudus yang berkonsentrasi pada aspek ulumul fiqh. Tujuan yang hendak dicapai adalah terbentuknya manusia yang berkarakter utuh (al-kaun al-jami') dan seimbang antara akal dan hati, jasmani dan rohani, keterampilan dan akhlak, serta kognitif, afektif dan psikomotorik. Ma'had Qudsiyyah telah menyiapkan proses dan manajemen pendidikan yang mencerminkan langkah-langkah pengelolaan, strategi implementasi, kesiapan SDM pendidikan dan kependidikan, indikator-indikator keberhasilan program, desain program yang komprehensif berisikan muatan dan analisis kontekstual proses pendidikan, teknik evaluasi program dan pengawasan dan formulasi kebijakan.
\end{abstract}

Kata kunci: pesantren, karakter pendidikan, pendidikan karakter 


\section{A. Pendahuluan}

Di tengah pesatnya kemajuan ilmu pengetahuan dan teknologi, dengan segala efek positif dan negatifnya, keniscayaan manusia masa depan yang tetap beriman dan bertakwa di satu sisi dan di sisi lain menjadi manusia yang cerdas, terampil, dan mandiri serta sanggup berkompetisi dengan yang lain adalah obsesi dan cita-cita yang tidak bisa ditawar lagi. Oleh karena itu, generasi masa depan harus dipersiapkan untuk mampu bertahan, bersaing dan memiliki kualitas serta mumpuni dalam bidang tertentu. Jika tidak, mereka akan terkooptasi oleh arus globalisasi dan modernisasi. Sejarah telah membuktikan bahwa konsistensi pesantren terhadap manhaj al-fikr al-salafy (metode berfikir sesuai nilai-nilai salaf) telah menjadikannya mampu bertahan dari segala deraan dan tantangan zaman. Pesantren dapat bertahan dengan tegar ketika sistem pendidikan yang lain hanya sibuk mengurusi politik dan birokrasi. Demikian pula, pesantren juga tetap hidup dengan moderasi dan toleransinya ketika muncul lembaga Islam lain yang justru mengarahkan peserta didiknya untuk tidak toleran terhadap umat lain.

Untuk mewujudkan idealitas tersebut perlu dibangun kekuatan pribadi-pribadi yang menjadi cikal bakal keluarga dan masyarakat. Mengingat pembangunan bangsa memerlukan individu dalam keluarga dan masyarakat yang saleh, yang layak memikul amanah yang dibebankan kepadanya, maka pembangunan pribadi menjadi sesuatu yang niscaya. Dan untuk mencapai harapan tersebut perlu adanya upaya serius dan bertanggungjawab karena ia adalah alat masyarakat yang terpenting dalam melaksanakan tugas sosial demi kepentingan dan tujuan bersama, memperkuat peradaban insani dan menegakkan nilai-nilai kebenaran. Kesalehan pribadi lahir dari ketakwaan yang bersifat individual sedangkan kesalehan masyarakat lahir dari ketakwaan yang bersifat kolektif. Mereka secara bersama-sama memiliki kesadaran sejarah, kesadaran tentang fakta sosial dan kesadaran tentang keharusan melakukan perubahan sebagai perwujudan kewajibannya sebagai makhluk moral dalam melaksanakan misi otentiknya, yaitu membangun peradaban.

Kudus, sebagai satu-satunya kota di Indonesia yang menggunakan kata Arab "quds", pernah tercatat mampu menanamkan nilai-nilai salafi, bahkan melahirkan tokoh-tokoh intelektual yang diakui secara regional dan internasional. $\mathrm{KH}$. 
Raden Asnawi, Ulama' besar kota Kudus yang pernah mukim di Makkah, telah menggagas berdirinya madrasah Qudsiyah pada tahun 1917 M. Mereka menjadi ulama besar yang benar-benar produktif dalam berkarya serta tetap tidak kehilangan orientasi praksis mereka. Mereka mampu memadukan antara iman dan amal saleh, serta antara rasionalitas dan spiritualitas. Lebih dari itu, mereka tetap tidak kehilangan kesederhanaan dan kerendahan hati mereka.

Sayangnya, eksistensi madrasah dari waktu ke waktu semakin tergerus oleh gelombang 'penyamarataan' atas nama akreditasi, Kurikulum Nasional dan Kurikulum Depag. Terlepas plus minus tiga hal tersebut, secara nyata dapat dirasakan bahwa kurikulum khas Qudsiyyah semakin berkurang karena harus berbagi. Ini belum termasuk hadirnya sindrom ujian nasional yang penyikapannya membutuhkan banyak energi. Sebagai ikhtiar untuk mempertahankan visinya melawan gerusan peradaban, Qudsiyyah mesti kembali ke khittah para pendirinya. Qudsiyyah mesti membangun suatu institusi baru yang diharapkan akan mampu menjawab kebutuhan umat dalam menyongsong masa depan, sehingga apa yang kita citakan bersama untuk merealisasikan kembali predikat Khairu Ummah yang Raḥmatan lil 'alamin dapat terlaksana. Gagasan ini kemudian ditindaklanjuti dengan lahirnya Ma'had Qudsiyyah Menara Kudus yang berkonsentrasi pada aspek ulumul fiqh .

Konsentrasi ini menjadi signifikan karena dari waktu ke waktu masyarakat terus dihadapkan pada problem hukum Islam seiring dengan percepatan peradaban, sehingga umat dapat melakukan pembacaan kreatif terhadap khazanahnya, mampu melakukan kontekstualisasi dalam peradaban modern yang terus mengepung, tidak terjebak pada pengentalan normatif dan romantisme masa lalu sehingga menyeretnya ke dalam perubahan yang tidak antisipatif.

\section{B. Antara Pendidikan Karakter dan Karakter Pendidikan}

Aksioma yang tak terbantahkan adalah bahwa pendidikan merupakan pilar bangsa. Setiap bangsa sangat menaruh harapan terhadap dunia pendidikan. Dari pendidikan inilah masa depan suatu bangsa dikontruksi dalam landasan yang kuat. Sebuah 
landasan yang mampu memandirikan anak bangsa dengan berbagai potensi yang dimilikinya. ${ }^{1}$

Undang-undang Nomor 20 Tahun 2003 tentang Sistem Pendidikan Nasional menyebutkan bahwa Pendidikan adalah usaha sadar dan terencana untuk mewujudkan suasana belajar dan proses pembelajaran agar peserta didik secara aktif mengembangkan potensi dirinya untuk memiliki kekuatan spiritual keagamaan, pengendalian diri, kepribadian, kecerdasan, akhlak mulia, serta keterampilan yang diperlukan dirinya, masyarakat bangsa dan negara (pasal 1, butir 1).

Pendidikan juga dapat diartikan sebagai proses pengubahan sikap dan tingkah laku seseorang atau sekelompok orang dalam usaha mendewasakan manusia melalui pengajaran dan latihan. Proses ini, dalam terminologi Arab, dikenal dengan istilah Tarbiyah yang secara keseluruhan menghimpun kegiatan yang terdapat dalam pendidikan, yaitu membina, memelihara, mengajarkan, menyucikan jiwa dan mengingatkan manusia terhadap hal-hal yang baik.

Tujuan yang hendak dicapai oleh pendidikan Islam adalah lahirnya manusia yang utuh; akal dan hatinya; rohani dan jasmaninya; akhlak dan keterampilannya; kognitif, afektif dan psikomotoriknya, sebagaimana ditemukan dalam teori al-Ikhwan al-Safa, ${ }^{2}$ al-Qabisi, ${ }^{3}$ dan al-Ghazali. ${ }^{4}$ Penambahan kata sifat

${ }^{1}$ Najib Sulhan, Pendidikan Berbasis Karakter, (Surabaya: Jepe Press Media Utama, 2010), hlm. 53.

2 Al-Ikhwan al-Safa merumuskan tujuan pendidikan adalah untuk menumbuhkembangkan kepribadian Muslim yang mampu mengamalkan citacitanya. Lihat M. Arifin, Ilmu Pendidikan Islam, (Jakarta: Bumi Aksara, 1994), hlm. 226.

${ }^{3}$ Nama lengkapnya adalah Abu al-Hasan 'Ali ibn Muhammad Illiful alMu'afiri (324-403 H/935-1001 M) merumuskan tujuan pendidikan adalah untuk mencapai makrifah dalam agama baik ilmiah maupun amaliah. Lihat Muhammad Munir Sa'du al-Din, al-Dirasah fi al-Tarikh al-Tarbiyah 'inda al-Muslimin, (Beirut: al-Maqriniyah, 1995), hlm. 217.

${ }^{4}$ Tujuan pendidikan menurut al-Ghazali adalah melatih agar anak dapat mencapai makrifat kepada Allah melalui jalan tasawuf. Sebutan "al-Ghazali" sebetulnya bukan nama aslinya. Nama aslinya adalah Muhammad saja. Tapi lebih dikenal dengan Abu Hamid. Bila disebut secara lengkap namanya adalah al-Imam Zainuddin Hujjat al-Islam Abu Hamid Muhammad bin Muhammad al-Ghazali al-Tusi al-Faqih al-Sufi al-Shafi'i al-Ash'ari. Ia lahir pada tahun $450 \mathrm{H} / 1059 \mathrm{M}$ di Ghazaleh, sebuah kota kecil yang terletak di dekat Thus di Khurassan empat setengah abad setelah Nabi Muhammad saw 
"Islam" pada "pendidikan" bukanlah sekedar tempelan yang tidak berarti. Tetapi mempunyai maksud mendalam yang meliputi bukan saja aspek "keagamaan" yang sering dipahami secara sempit, bahkan mencakup juga aspek "peradaban" yang luas. Oleh sebab itu pendidikan Islam juga adalah pendidikan yang lahir dari peradaban Islam atau tamaddun Islam, bukan sekedar pendidikan "agama" Islam.

Dengan demikian dapat dikatakan bahwa pada dasarnya pendidikan adalah cermin karakter bangsa. Pendidikan Islam adalah cermin peradaban masyarakat muslim. Hal ini bisa dipahami karena secara psikis seseorang cenderung memasukkan segala sesuatu yang berasal dari luar dirinya seperti simbol-simbol yang mencerminkan dunia di sekitarnya, norma, budaya, kehidupan sosial, serta perilaku orang yang akrab dengannya ke dalam sistem gejala kejiwaannya. Proses internalisasi pengalaman ini kemudian mempengaruhinya dengan cara tertentu ketika memahami, merasa, berpikir dan berbuat. $^{5}$ Dengan demikian, sistem pendidikan tidak lahir dari ruang hampa. Sistem pendidikan lahir dan dimunculkan oleh peradaban tertentu.

Ketika peradaban berubah menjadi sistem global, makan dunia pendidikan, termasuk Indonesia, dengan sendirinya dihadapkan pada problem baru yang tidak begitu nampak pada era

dari Mekkah ke Madinah dan kira-kira bersamaan dengan pengangkatan Sultan Alp Arselan ke singgasana Saljuk. Ia meninggal dunia pada usia sekitar lima puluh lima (55) tahun, pada tanggal 14 Jumadil akhir $505 \mathrm{H}$ atau 19 Desember $1111 \mathrm{M}$. Terkait dengan nama al -Ghazali ini, terdapat dua pandangan mengenai asal-usul kata "al-Ghazali" ini. Pendapat pertama, sebutan ini diambilkan nama desa kelahirannya, yaitu Ghazaleh (dengan satu "z"), seperti al-Kindi (berasal dari Kindah), al-Farabi (bersal dari Farab). Ada pendapat lain, julukan yang akrab untuk Imam yang agung itu berasal dari profesi ayahnya sebagai seorang penenun dan penjual kain tenun, yang oleh masyarakat Khurassan disebut "ghazzal" (dengan dua "z"). Ini sama dengan al-Qaffal (tukang kunci), al-Khayyam (pembuat khimah). Dalam tulisan ini yang digunakan adalah pendapat yang pertama. Lihat H. Zainal Abidin Ahmad, Riwayat Hidup Imam al-Ghazali, Jakarta: Bulan Bintang, 1975, 27-28; juga lihat Syamsun Ni'am, "Corak Tasawuf dan Pengaruhnya (Refleksi Tasawuf Sunni al-Ghazali)" dalam AULA, No. 03 Tahun XXIV Maret 2002 (PWNU Jatim), hlm. 56. Lihat Fatiyah Hasan Sulaiman, Alam Pikiran alGhazali Mengenai Pendidikan dan Ilmu, (Bandung: Diponegoro, 1986), hlm. 31 .

${ }^{5}$ Vinacke, The Psycholgy of Thinking, (Toronto: Mc Graw Hill Book Company Inc, 1992), hlm. 285. 
sebelumnya. ${ }^{6}$ Hal ini karena intensitas dan cakupannya menyentuh hampir seluruh sendi kehidupan. Tidak hanya bidang ekonomi, bisnis, budaya, politik, ideologi, melainkan juga telah menjamah ke tataran systems, processes, actors, dan events. ${ }^{7}$ sehingga di sana melahirkan banyak peluang sekaligus tantangan. ${ }^{8}$

Di antara tantangan yang paling krusial adalah masalah karakter anak didik. Tantangan globalisasi menjadikan pendidikan berkarakter menjadi bagian penting untuk mewujudkan manusia yang berkualitas. Istilah ini mudah diucapkan, tetapi sulit untuk dilakukan. Dalam kasus Madrasah Aliyah, hal ini antara lain disebabkan oleh adanya sistem dan model pendidikan yang tidak sesuai dengan peradaban mereka. Mereka dipaksa mengikuti kurikulum nasional, padahal dalam hatinya ingin kurikulum lokal yang lebih mencerminkan karakter stakeholdernya. Manajemen yang demikian, di samping tidak memberdayakan, juga akan menyebabkan turunnya produktivitas. Yang terjadi kemudian adalah satu di antara dua hal: split personality (pribadi terbelah) atau mengamini sistem mereka. Sebuah pilihan yang sama-sama tidak ideal. Split personality akan menyebabkan tindakan setengah-setengah, sementara yang kedua akan menghilangkan karakter komunitas Islam (ummah). ${ }^{9}$

${ }^{6}$ Kehadiran sistem global pendidikan menjadi semakin cepat karena faktor sistem global ekonomi. Di dunia ekonomi, sebenarnya globalisasi bukanlah suatu fenomena baru dalam sejarah peradaban dunia. Sebelum kemunculan nation-state perdagangan dan migrasi lintas benua telah sejak lama berlangsung. Jauh sebelumnya perdagangan regional telah membuat interaksi antarsuku bangsa terjadi secara alamiah. Sejak masa sejarah modern, khususnya sebelum memasuki abad ke-20 ini, globalisasi dipandang sebagai gelombang masa depan. Dua dekade sebelum Perang Dunia I, arus uang internasional telah mengikatkan Eropa lebih erat dengan Amerika Serikat, Asia, Afrika, dan Timur Tengah. Pasar modal mengalami booming di kedua sisi Atlantik, sementara itu bank dan investor-investor swasta sibuk mendiversifikasikan investasinya dari Argentina hingga Singapura. Jeffrey E. Garten, "Why the Global Economy is Here to Stay," dalam Business Week, March 23, 1998: 9; Collin Rose dan Malcolm J. Nicholl, Accelerated Learning for the 21 st Century, (New York: Delacorte Press, 1997), hlm. 1.

7 Jan Pronk, "Globalization: A Developmental Approach", dalam Jan Nederveen Pieterse (ed.), Global Futures, Shaping Globalization, (London: Zed Books, 2001), hlm. 43.

${ }^{8}$ Walter Leimgruber, Between Global and Local, (England: Ashgate Publishing Limited, 2004), hlm.18-19.

${ }^{9}$ Konsep Ummah dalam Islam mengandung 5 nilai dan 4 sifat dasar. Lima nilai tersebut adalah universalisme, egalitarianisme, non etnosentrisme, 
Akibat dari munculnya fenomena tersebut tampak dalam kegelisahan Direktur Jenderal PMPTK Depdiknas. Dia menyatakan bahwa saat ini ada kecenderungan masyarakat maupun sekolah sekadar memacu siswa untuk memiliki kemampuan akademik tinggi tanpa diimbangi pembentukan karakter yang kuat dan cerdas. Upaya sekolah maupun orang tua agar murid atau anaknya mencapai nilai akademis tinggi sangat kuat, tapi mengabaikan hal-hal yang non akademis. ${ }^{10}$

Oleh karena itu, menjadi sangat beralasan jika kemudian pendidikan karakter ini semakin menampakkan urgensitasnya. Pemerintah pun menunjukkan komitmennya dengan lahirnya Undang-undang Nomor 20 Tahun 2003 tentang Sistem Pendidikan Nasional. Dalam Pasal 3 UU tersebut dinyatakan bahwa "Pendidikan nasional berfungsi mengembangkan kemampuan dan membentuk watak serta peradaban bangsa yang bermartabat dalam rangka mencerdaskan kehidupan bangsa, bertujuan untuk berkembangnya potensi peserta didik agar menjadi manusia yang beriman dan bertakwa kepada Tuhan Yang Maha Esa, berakhlak mulia, sehat, berilmu, cakap, kreatif, mandiri, dan menjadi warga negara yang demokratis serta bertanggung jawab."

Secara filologis, istilah karakter diasosiasikan dengan temperamen yang menekankan unsur psikologial. Seseorang juga bisa memahami karakter dari sudut pandang behavioral yang menekankan unsur somatopsikis yang dimiliki individu sejak lahir. $^{11}$

totalitarianisme, dan transendentalisme. Sedangkan 4 nilai dasarnya adalah komprehensif, kontekstualis, dinamis dan organis. Fatah, Kewargaan Dalam islam, (Surabaya: lpam, 2004),132-175; Sa'id Aqiel Siraj, Islam Kebangsaan: Fiqh Demokratik Kaum Santri, (Jakarta: Pustaka Ciganjur, 1999), hlm. 219-230.

${ }^{10}$ Banyak kasus ekstrim yang membenarkan sinyalemen di atas. Mulai dari kasus tawuran pelajar dan mahasiswa, perjokian dalam penerimaan mahasiswa baru atau pegawai negeri, penyuapan, makelar kasus dan perkara, perselingkuhan, korupsi dan drama memalukan anggota DPR yang sebenarnya memiliki latar pendidikan tinggi, namun memiliki karakter perilaku yang rendah. Semua itu menggambarkan kegagalan pendidikan kita dalam membangun karakter bangsa. Bahkan bila dicermati, penolakan dan ketakutan yang berlebihan terhadap pelaksanaan ujian nasional juga merupakan cermin kegagalan pendidikan kita.

${ }^{11}$ Doni Koesoema A, Pendidikan Karakter ; Strategi Mendidik Anak di Zaman Global, (Jakarta: Grasindo, 2007), hlm. 80. 
Dalam kamus besar bahasa Indonesia, karakter didefinisikan sebagai tabiat; sifat-sifat kejiwaan, akhlak atau budi pekerti yang membedakan seseorang dengan yang lain; watak, sedang kata berkarakter diterjemahkan sebagai mempunyai tabiat; mempunyai kepribadian; berwatak. Di dalam kamus psikologi dinyatakan bahwa karakter adalah kepribadian ditinjau dari titik tolak etis atau moral, misalnya kejujuran seseorang; biasanya mempunyai kaitan dengan sifat-sifat yang relatif tetap. ${ }^{12}$

\section{Pendidikan Karakter dalam Dunia Global}

Istilah karakter sendiri sesungguhnya menimbulkan ambiguitas. Karakter, secara etimologis berasal dari bahasa Yunani "karasso", berarti "cetak biru", "format dasar", "sidik" seperti dalam sidik jari. Sedangkan menurut istilah, ada beberapa pengertian mengenai karakter itu sendiri. Secara harfiah Hornby dan Parnwell mengemukakan karakter artinya "kualitas mental atau moral, kekuatan moral, nama atau reputasi" 13

Dalam Islam, kata yang paling dekat untuk menunjukkan karakter adalah akhlak. Al-khulq (bentuk mufrad/tunggal dari kata akhlak) berarti perangai, kelakuan, dan gambaran batin seseorang. Pada dasarnya manusia itu mempunyai dua gambaran, yakni gambaran lahir dan gambaran batin. Gambaran lahir berbentuk tubuh yang nampak secara fisiologis, sementara gambaran batin adalah suatu keadaan dalam jiwa yang mampu melahirkan perbuatan, baik yang terpuji maupun tercela. ${ }^{14}$

Eksistensi akhlak, dalam perspektif ilmu pengetahuan modern, terhubung dengan 'modul Tuhan' atau 'God Spot'. Dikatakan bahwa dalam struktur batin manusia ada jaringan syaraf yang berkaitan dengan pengalaman religi atau spiritual. Michael Persinger (Cambridge University) dan Ramachandran (California University) menyebutnya sebagai "God-spot" (titik Tuhan/modul Tuhan). Modul ini bersifat built in, semenjak pre-existence, atau sejak nur cahya putih wujud ingsun, atau sejak masih di alam

${ }^{12}$ M. Furqon Hidayatullah, Guru Sejati: Membangun Insan Berkarakter Kuat dan Cerdas, (Surakarta: Yuma Pustaka, 2009), hlm. 9.

${ }^{13}$ Hidayatullah, Guru Sejati: Membangun Insan ..., hlm. 49.

${ }_{14}$ Muhammad bin Shalih, Makarim al-Akhlaq, (Kairo: Dar al-Ma'arif, 2001), hlm. 1 
dzar. Dalam istilah al-Ghazali, akhlak berkoneksi dengan nafs yang kemudian berinteraksi dengan $r u h$, 'aql dan qalb. ${ }^{15}$

Jenis karakter yang hendak ditanamkan pada siswa, sebagaimana anjuran kementrian diknas, adalah: pertama, karakter cinta Tuhan dan segenap ciptaan-Nya; kedua, kemandirian dan bertanggungjawab; ketiga, kejujuran/ amanah, diplomatis; keempat, hormat dan santun; kelima, dermawan, suka tolongmenolong dan gotong-royong/kerjasama; keenam, percaya diri dan pekerja keras; ketujuh, kepemimpinan dan keadilan; kedelapan, baik dan rendah hati, dan; kesembilan, karakter toleransi, kedamaian, dan kesatuan.

Untuk menanamkan pendidikan karakter tersebut, mutlak diperlukan kualitas proses dan manajemen pendidikan yang setidaknya mengakomodir: 1) langkah-langkah pengelolaan; 2) Strategi implementasi; 3) kesiapan SDM pendidikan dan kependidikan; 4) indikator-indikator keberhasilan program; 5) Desain Program yang komprehensif berisikan muatan dan analisis kontekstual proses pendidikan; 6) teknik evaluasi program dan pengawasan; 7) formulasi kebijakan yang harus menunjang proses pelaksanaan pendidikan karakter.

Dari 7 prasayarat tersebut, penulis memahami bahwa kunci utama keberhasilan pendidikan karakter terletak pada keteladanan seorang pendidik kepada anak didik, dalam hal ini yaitu guru kepada siswa. Keteladanan merupakan metode yang paling berpengaruh dalam mempersiapkan dan membentuk aqidah akhlak. Jadi, Contoh akhlak yang paling dekat yaitu guru/pendidik,

15 al-qalb dipergunakan untuk dua pengertian: a. segumpal daging di samping kiri dada, di dalamnya ada rongga berisi darah yang menjadi asal usul ruh; b. makna kedua adalah lathifah rabbaniah bersifat ruhaniah yang merupakan hakikat kemanusiaan. Term al-ruh dipakai dalam dua arti: a. menunjuk pada jenis halus yang bersumber dari rongga hati jasmaniah manusia; b. unsur halus kemanusiaan yang mampu mengetahui atau memahami. Term al-nafs dipahami sebagai pengertian umum dari dorongan kemarahan atau nafsu, dan pengertian kedua menujuk pada ragam karakternya menjadi al-nafs al-mutmainnah, al-lawwamah, serta nafs al-ammarah. Sedangkan terminologi al- 'aql dipahami sebagai konsep tentang kemampuan batiniah kemanusiaan dimengerti dengan dua pengertian: a. pertama dipahami sebagai materi pengetahuan tentang berbagai hal yang menjadi muatan kalbu; b. sering pula dipahami sebagai pelaku pemahaman, pengertian, pengetahuan dan lain-lain yang tidak lain wujudnya adalah hati (qalb) itu sendiri. al-Ghazali, Ihya' 'Ulum al-Din, vol. I, (Surabaya: al-Hidayah, 1987), hlm. 152-9; bandingkan dengan, al-Ghazali, Ihya, vol. III, hlm. 3-7. 
sehingga diharapkan peserta didik akan mampu meniru pendidik dengan disadari atau tidak. Hal tersebut dikarenakan subjek didik tidak begitu saja lahir sebagai pribadi bermoral atau berakhlak mulia, tetapi perlu berproses, bermetamorfosa sampai bertransformasi menjadi pribadi yang berkarakter positif. ${ }^{16}$

Keteladanan yang paling nampak adalah karakter yang dimainkan oleh si guru dan institusinya. Sebaik apapun konsep pendidikan (termasuk karakter), jika institusi penyelenggaranya tidak berkarakter, pastilah hasilnya tidak maksimal. Karakter pendidikan merupakan suatu kualitas atau sifat yang secara kontinu dilakukan sehingga dapat dijadikan ciri untuk mengidentifikasi suatu objek atau suatu kejadian.

\section{Pendidikan Karakter dalam Lembaga Pendidikan Islam}

Karakter pendidikan terkait dengan formasi pendidikan. Formasi di sini dipahami sebagai bentuk, figur, penampakan, pola dan kerangka. Jika dihubungkan dengan pendidikan, maka kata formasi memiliki makna kerangka rancang bangun unsur-unsur pembentuk pendidikan, ${ }^{17}$ yang menunjuk pada fenomena fisiologis, psikologis, sosiologis, dan antropologi. Dengan demikian, karakter pendidikan merupakan susunan unsur yang saling berinterelasi dan bergantung sehingga membentuk sifat khas dalam mencapai tujuannya, ${ }^{18}$ baik pada level individu ${ }^{19}$ maupun sosial. $^{20}$

Kekhasan pendidikan inilah yang seringkali luput dari perhatian. Jika yang menjadi fokus perhatian adalah pendidikan karakter, sementara karakter pendidikannya luput dari sorotan, maka yang terjadi kemudian adalah penyeragaman karakter dari institusi yang tidak berkarakter, setidaknya karakternya tidak jelas. Ini sesuatu yang mengkhawatirkan. Mengapa? Karena manusia

${ }^{16}$ Tonny D. Widiastono, Pendidikan Manusia Indonesia, (Jakarta: Buku Kompas, 2004), hlm. 42.

17 Dogobert D. Runes, Digtionary of Philosophy (New Jersey: Litle Field Adams Co, 1976), hlm. 111.

${ }^{18}$ Ernest Nagel, The Structur of Science, (London: Routledge \& Kegan Paul, 1984), hlm. 528.

19 Peter D. Spear, Psychology; Perspective on Behavior (New York: John Willeys and Sons, 1998), hlm. 6.

${ }^{20}$ Robert K. Merton, Social Theory and Social Structure (London: Collier Macmillan Publishers, 1968), hlm. 41. 
dengan seperangkat pendidikan yang berada di lingkungan dan tradisinya adalah sebuah sistem yang kompleks. Manusia berposisi sebagai sistem hidup yang memiliki kompleksitas sifat unik, ${ }^{21}$ yang dengan sendirinya membutuhkan teori kompleksitas untuk memahaminya. ${ }^{22}$

Secara sederhana, dapat dikatakan bahwa sebuah sistem dikatakan kompleks jika sistem itu terdiri dari banyak komponen atau subunit yang saling berinteraksi dan mempunyai perilaku yang menarik. Namun, pada saat yang bersamaan, tidak kelihatan terlalu jelas jika dilihat sebagai hasil dari interaksi antar subunit yang diketahui. ${ }^{23}$

Bruce Edmonds (1999) menawarkan definisi kompleksitas sebagai sifat dari sebuah model yang membuatnya sulit untuk memformulasikan perilaku keseluruhan dalam representasi bahasa yang ada, bahkan dengan informasi yang lengkap tentang komponen-komponen dan interelasi di dalamnya. Pavard dan Dugdale (2002) memberikan definisi bahwa sistem kompleks adalah sistem yang sulit dan tidak mungkin membatasi deskripsi tentang sistem tersebut dengan beberapa parameter tanpa kehilangan hal fungsional dan esensialnya secara keseluruhan. Hal ini karena ia disusun oleh komponen-komponen penyusun yang saling berinteraksi satu sama lain sehingga menghasilkan faktorfaktor global sistem yang membrojol (emergent) dalam dinamikanya. ${ }^{24}$

Untuk memahami sistem tersebut, memahami interaksi antar unit di dalamnya, kita bisa menggunakan metafora mobil. Unsur

${ }^{21}$ Untuk mendefinisikan manusia saja terjadi simplifikasi jika dibandingkan dengan keseluruhan (jam 'iyyah)-nya. Makhluk apa pun dalam kosmos tak akan mampu memahami manusia dengan berbagai misterinya. Kompleksnya manusia, bahkan sejak belum menjadi manusia sempurna ketika diciptakan, memberi ruang yang lebar untuk disalahpahami. Dalam alQur'an, malaikat dan iblis tidak dapat memahami manusia. Muhyiddi bin 'Arabi, Fusus al-Hikam (Beirut: Dar al-Kitab al-'Arabi, tt), hlm. 50-51.

${ }^{22}{ }^{22}$ Kompleksitas merupakan kajian atau studi terhadap sistem kompleks. Kata 'kompleksitas' berasal dari kata Latin complexus yang artinya "totalitas" atau "keseluruhan"; sebuah ilmu yang mengkaji totalitas sistem dinamik secara keseluruhan.

${ }^{23}$ Vladimir Dimitrov, A New Kind of Social Science: Study of SelfOrganization in Human Dynamics (Berlin: Springer-Verlag, 2003), hlm. 76.

24 Edmonds, Bruce Syntactic Measures of Complexity, tesis Ph.D. disampaikan kepada Faculty of Arts, University of Manchester, 1999, hlm. 211. 
pembentuk mobil berinteraksi secara kompleks untuk menghasilkan gerak. Sistem kompleks mekanis semacam itu bersifat nonadaptif sistem seperti itu tak belajar, tak berkembang. Bagian-bagian individual yang merupakan komponen dari sistem itu tidak bisa berubah melalui interaksi antar bagian itu atau interaksi dengan lingkungan.

Berkebalikan dengan sistem yang mekanistis, baik sederhana maupun kompleks, sistem adaptif bisa beradaptasi dan berkembang. Model mutasi genetik Darwin melukiskan sistem semacam itu. Satu gen tunggal kadang kala mengalami satu mutasi acak. Lingkungan tempat gen tersebut berada tak terpengaruh, tetapi gen itu sendiri, dan dengan begitu keseluruhan organisme, berubah.

Dengan melihat secara lebih detil, akhirnya para pakar biologi kompleksitas menemukan sejenis sistem yang dikenal sebagai "sistem adaptif kompleks". Sistem-sistem ini punya banyak bagian yang berinteraksi dan selalu berada dalam dialog yang kreatif dengan lingkungan mereka. Ketika lingkungan memicu krisis dalam sistem, keseluruhan mega-sistem (organisme, lingkungan dan elemen-elemen di dalamnya) berevolusi bersama. ${ }^{25}$

Sistem-sistem adaptif kompleks ini bersifat nonlinear. Mereka tak bisa diprediksi; upaya-upaya untuk mengendalikan mereka justru akan berdampak destruktif, dan mereka tak bisa dipecahpecah ke dalam bagian-bagian yang lebih sederhana dan terpisah. Sebuah sistem hidup yang berada di ambang chaos harus dilihat sebagai satu keutuhan, dan bahwa keutuhan itu lebih besar ketimbang himpunan dari bagian-bagiannya. ${ }^{26}$

Jika sistem sederhana Newtonian dirancang berdasarkan cetak biru atau mengikuti tiga hukum gerak Newton, maka sistem adaptif kompleks muncul melalui pengaturan diri (selforganization). Jika sistem Newtonian bersifat konstan dalam semua keadaan, tak pernah memungkinkan adanya perubahan internal, maka sistem adaptif kompleks secara kreatif mengeksplorasi masa depannya sendiri seraya beradaptasi dan berkembang dalam sebuah lingkungan yang mereka sendiri

${ }^{25}$ Danah Zohar, Spiritual Capital; memberdayakan $S Q$ di dunia Bisnis (Jakarta: Mizan, 2009), hlm. 131.

${ }^{26}$ Robert Axelrod, The Complexity of Cooperation: Agent-Based Models of Competition and Colaboration (Princeton University Press. 1997), hlm. 4. 
sensitif secara internal. Jika sistem sederhana Newtonian bersifat stabil, sistem kompleks bisa secara radikal bersifat tidak stabil, dan instabilitasnya memungkinkannya untuk bergerak ke ambang chaos.

Saat ini, ada kecenderungan semakin menurunnya vitalitas pesantren di tengah kehidupan umatnya yang dirundung bermacam-macam persoalan. Pesantren sebagai motor kebangkitan juga terlihat kian memudar. Model kajian keislaman yang njlimet memakai pendekatan nahwu sharf semakin tidak menarik. Sebagai penggantinya, lahirlah pesantren kilat dan gairah rohis (rohani Islam) yang menawarkan tafsir instant. Yang lebih memprihatinkan, Pesantren juga mulai ikut 'berebut pasar', sehingga perlu merapat dengan kekuasaan.

Sebagai sebuah pengamatan subyektif, saya merasakan pesantren memiliki 5 karakter yang memberi mereka modus operasi kreatif dalam menatap dunia. Alam pikiran mereka terstruktur kreatif ketika bertemu dengan medan makna sehingga memberi peluang untuk mengubah paradigma dan membentuk paradigma baru. Kelima karakter tersebut adalah:

1. Pengaturan diri (self-organizing). Pesantren memiliki karakter kemandirian untuk menata dirinya sendirinya. Akan tetapi, tatanan tersebut masih berupa energi potensial yang kemudian bisa mengambil bentuk apa pun, sesuai kebutuhan dan lingkungan.

2. Instabilitas terbatas. Karakter di pesantren sebenarnya masih dalam sebuah zona instabilitas yang berada tepat di antara keteraturan dan chaos. Jika sistem di lingkungan pesantren tersebut tidak stabil, karakter tersebut akan tercerai-berai ke dalam chaos. Sebaliknya, dalam iklim stabil, karakter tersebut akan beradaptasi dengan keteraturan.

3. Holistik. Karakter pesantren sebenarnya tak punya batas-batas internal dan tidak dapat ditentukan bagian-bagian terpisahnya. Tiap-tiap bagian terlibat dan bersinggungan dengan bagianbagian lain. Bagian-bagian itu ditentukan secara internal melalui hubungan satu sama lain dan hubungan dengan lingkungan.

4. Adaptif. Sistem-sistem ini tak hanya belajar ketika bekerja, sistem-sistem ini juga mencipta diri mereka sendiri ketika mereka beraktivitas untuk mengeksplorasi masa depan mere- 
ka sendiri. Adaptasi ini selalu berada dalam kondisi yang swakreatif (self-creative) dengan lingkungan yang sebenarnya ia sensitif secara internal.

5. Eksploratoris. Sistem karakter pesantren senantiasa mengeksplorasi kemungkinan masa depan mereka sendiri dan mencipta diri mereka sendiri sembari berjalan. Mereka akan membingkai ulang dan melakukan dekontekstualisasi dalam batas-batas dan sifat-sifat lingkungan mereka.

Sudah saatnya kita merevitalisasi, bahkan mentransformasi karakter pendidikan pesantren. Kita mesti selalu mencari dan menawarkan terobosan-terobosan baru yang segar dan relevan guna memulihkan vitalitas pesantren. Sampai di sini saya teringat usul Muhammad Abid al-Jabiri untuk menyandingkan secara kritis pendekatan modern dengan khazanah tradisi Islam klasik. Dengan pendekatan strukturalis, historis dan kritis, ia yakin bahwa cara tersebut pada gilirannya akan sampai pada lahirnya tradisi baru hasil sintesa khazanah intelektual Islam klasik dengan segala pemikiran yang berkembang dewasa ini. Tradisi tersebut akan menjadi perangkat praksis yang membebaskan manusia.

Pribumisasi Islam yang pernah digagas oleh Abdurrahman Wahid perlu kita angkat kembali dan diperteguh menjadi Islam pribumi. Apa yang dilakukan Kiyai Masrur dari Cangkringan, Pakem, Sleman, Yogyakarta perlu disuritauladani. Jatilan yang selama ini nyaris identik dengan budaya musyrik didialogkan secara intens dengan nilai-nilai Islam, sehingga yang muncul adalah seni-budaya Jawa yang mengemban transformasi nilai-nilai Islam substansial, sekalipun menurut sebagian orang hal tersebut disebut bid' $a h^{27}$.

Tugas kita justru mentransformasi dan menaikkan daya tarik tradisi tersebut kepada dunia karena pesantren merefleksikan dua bentuk keislaman sekaligus, yakni Islam official dan

${ }^{27}$ Kesenian ini merupakan pertunjukan yang diiringi musik tradisional Jawa di mana pemainnya mengalami trance (ndadi) yang dipercayai karena masuknya makhluk halus. Dalam keadaan trance itu, adegan yang atraktif dan mendebarkan muncul, seperti makan kaca, menusuk diri sendiri dengan pisau, menelan bara api, dan dikubur seperti orang mati dalam beberapa saat. Lihat, "Bila Pesantren Mengelus Jatilan" Majalah Kebudayaan Desantara, (Edisi I, 2001), hlm. 07. 
Islam populer. ${ }^{28}$ Islam official adalah praktik keagamaan yang memiliki landasan normatif yang tertuang secara eksplisit dalam al-Qur'ān dan hadis. Kata official berarti law full, yang berarti secara hukum memiliki landasan normatif yang bisa dipertanggungjawabkan. Sementara Islam populer adalah praktik keagamaan yang diyakini tidak memiliki landasan langsung secara normatif dari al-Qur'an atau hadis. ${ }^{29}$

${ }^{28}$ Gellner menyebut Islam ofisial dengan istilah Islam ulama (scholarly Islam) dan Islam populer dengan istilah Islam rakyat (folk Islam). Sementara Moller menggunakan istilah Islam normatif (normative Islam) untuk Islam ofisial (official Islam) dan Islam nyata (lived Islam) untuk Islam populer (popular Islam). Robert Redfield, Peasant Society and Culture: An Anthropological Approach to Civilization (Chicago: the University of Chicago Press, 1956), hlm. 70.“Official and Popular Religion as a Problem in Islamic Studies" dalam Official and Popular Religion, ed. Pieter H. Vrijhof and Jacques Waardenburg (Paris: Mouton Publisher, 1979), 356-358; Ernest Gellner, Muslim Society (Cambridge: Cambridge University Press, 1981), hlm. 5.

${ }^{29}$ Untuk menjelaskan disparitas antara kedua macam ritual tersebut, agaknya kita bisa menggunakan konstruksi epistemologi yang diusulkan oleh Mark R. Woodward, yakni Islam universal, Islam esensial, Islam received dan Islam lokal. Islam universal adalah yang terkategorikan sebagai Arkān al-Isläm dengan ajaran dan muatan ajaran yang sudah ditentukan jenis, cara, ruang dan waktunya. Ritual yang demikian, dalam konteks pemahaman fiqih disebut sebagai ibadah mahdah. Islam esensial merujuk kepada modus praktek-praktek ritual yang tidak dimandatkan oleh sumber utama (primary source) Islam, termasuk kategori ini adalah, maulid Nabi, perayaan Muharram, ziarah dengan berbagai macam asesorisnya dan lain-lain. Sementara itu, Islam received adalah suatu konsep Islam yang menjembatani antara Islam universalis dan Islam esensiali dengan Islam lokal. Sebagai contoh dominasi ajaran sufi yang mempengaruhi perkembangan Islam di Jawa. Islam jenis ini bersifat dinamis, ia berubah seiring dengan perubahan pengetahuan dan penafsiran terhadap teks-teks tertulis. Yang terakhir, Islam lokal adalah seperangkat teks tertulis yang terdiri dari oral atau ritual yang kehadirannya tidak dikenal di daerah asal turunnya Islam (Saudi Arabia). Menurut R. Woodward, naskah atau tradisi mistik kejawen merupakan contoh yang paling jelas tentang Islam lokal ini, karena merupakan implikasi logis sebagai hasil interaksi antara kebudayaan dan received Islam, maka apa yang disebut sebagai ritual Islam, baik formal maupun populer, bisa dipahami secara proporsional sehingga tidak memunculkan klaim teologis sepihakAndre Moller, Ramadan di Jawa, terj. Salomo Simanungkalit (Jakarta: Nalar, 2005), hlm. 41; Masdar Helmi, "Problem Metodologis dalam Kajian Islam", dalam Paramedia, Jurnal Komunikasi dan Informasi Keagamaan (Surabaya, Pusat Penelitian UIN Sunan Ampel, 2000), hlm. 6-8. 
Dengan cara pandang demikian, terbuka peluang untuk menyingkap, memaknai dan melaksanakan agama sesuai konteks masa kini. Yang perlu dicatat adalah bahwa cara pikir ini menuntut hadirnya epistemologi holistis yang mengakomodasi aspek rasional, empiris, dan intuitif yang senantiasa didialogkan secara sirkular, sesuai dengan objeknya, baik materiil ataupun formil.

\section{E. Kesimpulan}

Eksistensi lembaga pendidikan Islam dari waktu ke waktu semakin tergerus oleh gelombang 'penyamarataan' atas nama akreditasi. Sebagai ikhtiar untuk mempertahankan visinya melawan gerusan peradaban, lembaga pendidikan Qudsiyyah akhirnya kembali ke khittah dengan mendirikan Ma'had Qudsiyyah Menara Kudus yang berkonsentrasi pada aspek ulumul figh. Tujuan yang hendak dicapai adalah terbentuknya manusia yang berkarakter utuh (alkaun al-jami') dan seimbang antara akal dan hati, jasmani dan rohani, keterampilan dan akhlak, serta kognitif, afektif dan psikomotorik. Ma'had Qudsiyyah telah menyiapkan proses dan manajemen pendidikan yang mencerminkan langkah-langkah pengelolaan, strategi implementasi, kesiapan SDM pendidikan dan kependidikan, indikator-indikator keberhasilan program, desain program yang komprehensif berisikan muatan dan analisis kontekstual proses pendidikan, teknik evaluasi program dan pengawasan dan formulasi kebijakan.

Poin ini perlu mendapat catatan tersendiri mengingat paradigma humanisme-sekuler telah mereduksi realitas-ontologis kepada hal yang bersifat fisik semata. Mereka membangun dunia dengan merujuk secara utuh kepada logos. Logos tentunya penting dalam kehidupan, karena ia merupakan pemikiran rasional, pragmatis dan scientific yang memungkinkan umat manusia berfungsi dengan baik dalam kehidupan dunia. Namun logos juga memiliki keterbatasan karena ia tidak mampu mengurangi kesedihan dan kepedihan penderitaan manusia. Argumen rasional tidak mampu memahami (make no sense) terhadap tragedi, sebagaimana pula ia tidak mampu menjawab pertanyaan tentang nilai akhir kehidupan manusia. Dengan demikian, yang dibutuhkan sekarang adalah sikap eklektik dan terbuka, bukan sikap dogmatis yang apatis terhadap tradisi. Wallahu A'lam 


\section{Kepustakaan}

Al-Ghazali. 1987. Ihya' 'Ulum al-Din. vol. I. Surabaya: alHidayah.

Arifin, M. 1994. Ilmu Pendidikan Islam. Jakarta: Bumi Aksara. Majalah Kebudayaan Desantara. 2001. Edisi I.

Axelrod, Robert. 1997. The Complexity of Cooperation: Agent Based Mod-els of Competition and Colaboration, Princeton University Press.

Collin Rose dan Malcolm J. Nicholl. 1997. Accelerated Learning for the 21 st Century. New York: Delacorte Press.

D. J. Waardenburg. 1979. Official and Popular Religion as a Problem in Islamic Studies dalam Official and Popular Religion. ed. Pieter H. Vrijhof and Jacques Waardenburg, Paris: Mou-ton Publisher.

Edmonds, Bruce. 1999. Syntactic Measures of Complexity. tesis doktoral $(\mathrm{P} h D)$ disampaikan kepada Faculty of Arts. University of Manchester.

Fatah. 2004. Kewargaan Dalam islam. Surabaya: lpam.

Fatiyah, Hasan Sulaiman. 1986. Alam Pikiran al-Ghazali Mengenai Pendidikan dan Ilmu. Bandung: CV. Diponegoro.

Garten, Jeffrey E. 1998. Why the Global Economy is Here to Stay. dalam Business Week. March 23.

Gellner, Ernest. 1981. Muslim Society. Cambridge: Cambridge Univer-sity Press.

Helmi, Masdar. 2000. Problem Metodologis dalam Kajian Islam, dalam Paramedia Jurnal Komunikasi dan Informasi Keagamaan.

Hidayatullah, M. Furqon. 2009. Guru Sejati: Membangun Insan Berkarakter Kuat dan Cerdas. Surakarta: Yuma Pustaka.

Koesoema A, Doni. 2007. Pendidikan Karakter ; Strategi Mendidik Anak di Zaman Global. Jakarta: PT Grasindo.

Leimgruber, Walter. 2004. Between Global and Local, England: Ashgate Publishing Limited.

Merton, Robert K. 1968. Social Theory and Social Structure. London: Collier Macmillan Publishers.

Moller, Andre. 2005. Ramadan di Jawa. terj. Salomo 
Simanungkalit. Jakarta: Nalar.

Muhammad, bin Saleh. 2001. Makarim al-Akhlaq. Kairo: dar alMa'arif.

Munir, Sa'du al-Din. 1995. al-Dirasah fi al-Tarikh al-Tarbiyah 'inda al-Muslimin, Beirut: al-Maqriniyah.

Nagel, Ernest. 1984. The Structur of Science. London: Routledge \& Kegan Paul.

Pronk, Jan. 2001. Globalization: A Developmental Approach, dalam Jan Nederveen Pieterse (ed.). Global Futures, Shaping Global-ization. London: Zed Books.

Redfield, Robert. 1956. Peasant Society and Culture: An Anthropological Approach to Civilization. Chicago: the University of Chi-cago Press.

Runes, Dogobert D. 1976. Digtionary of Philosophy, New Jersey: Litle Field Adams Co.

Siraj, Sa'id Aqiel. 1999. Islam Kebangsaan: Fiqh Demokratik Kaum Santri, Jakarta: Pustaka Ciganjur.

Spear, Peter D. 1998. Psychology; Perspective on Behavior. New York: John Willeys and Sons.

Sulhan, Najib. 2010. Pendidikan Berbasis Karakter. Surabaya: PT. Jepe Press Media Utama.

Surabaya: Pusat Penelitian UIN Sunan Ampel.

Vinacke. 1992. The Psycholgy of Thinking. Toronto: Mc Graw Hill Book Company Inc.

Vladimir Dimitrov. 2003. A New Kind of Social Science: Study of Self-Orga-nization in Human Dynamics. Berlin: Springer Verlag.

Widiastono, Tonny D. 2004. Pendidikan Manusia Indonesia. Jakarta: Buku Kompas.

Zohar, Danah. 2008. Spiritual Capital; memberdayakan SQ di dunia Bisnis. Jakarta: Mizan 
